\title{
Demonstration of glucose-6-phosphate dehydrogenase in rat Kupffer cells by a newly-developed ultrastructural enzyme-cytochemistry
}

\author{
S. Matsubara, ${ }^{*}$ D. Matsubara, ${ }^{*}$ T. Ishibashi, ${ }^{\circ}$ T. Takizawa ${ }^{\S}$

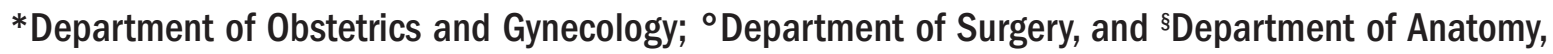 \\ Jichi Medical School, Tochigi, Japan
}

(C)2003, European Journal of Histochemistry

Although various tissue macrophages possess high glucose6-phosphate dehydrogenase (G6PD) activity, which is reported to be closely associated with their phagocytotic/bactericidal function, the fine subcellular localization of this enzyme in liver resident macrophages (Kupffer cells) has not been determined. We have investigated the subcellular localization of G6PD in Kupffer cells in rat liver, using a newly developed enzyme-cytochemical (copper-ferrocyanide) method. Electron-dense precipitates indicating G6PD activity were clearly visible in the cytoplasm and on the cytosolic side of the endoplasmic reticulum of Kupffer cells. Cytochemical controls ensured specific detection of the enzymatic activity. Rat Kupffer cells abundantly possessed enzyme-cytochemically detectable G6PD activity. Kupffer cell G6PD may play a role in liver defense by delivering NADPH to NADPH-dependent enzymes. G6PD enzyme-cytochemistry may be a useful tool for the study of Kupffer cell functions.

Key words: glucose-6-phosphate dehydrogenase, Kupffer cells, enzyme-cytochemistry

Correspondence: Shigeki Matsubara, Department of Obstetrics, Gynecology and Anatomy, Jichi Medical School, Minamikawachi-machi 3311-1, Kawachi-gun, Tochigi 3290498, Japan.

Phone: international +81-285-58-7376. Fax: international +81-285-44-8505. E-mail: matsushi@jichi.ac.jp

Paper accepted on September 6, 2002.

European Journal of Histochemistry 2003; vol. 47 issue 2 [Apr-Jun]:173-176
G lucose-6-phosphate dehydrogenase (G6PD; E.C. 1.1.1.49) catalyzes the conversion of glucose-6-phosphate to 6-phosphogluconate, with the production of NADPH, an essential substrate/co-factor for NADPH-dependent oxidoreductase enzymes including NADPH oxidase and nitric oxide synthase. Biochemical data indicated that monocytes/various tissue macrophages including liver resident macrophages (Kupffer cells) possess G6PD activity and that this activity is closely associated with their phagocytotic/bactericidal capacity (Spolarics and Navarro 1994; Curnutte 1995; Spolarics 1996). Although light microscopic enzyme-histochemistry roughly localized G6PD to Kupffer cells in rats (Hosemann et al. 1979), definite morphological evidence of its presence in these cells at the electron microscopic level has not been reported. We have investigated the subcellular localization of G6PD in rat Kupffer cells, using a newly developed G6PD enzyme-cytochemistry (the copper ferrocyanide method) (Ishibashi et al. 1999).

\section{Materials and Methods}

Five 7-week old male Sprague-Dawley rats (weighing 200-220g) were used for this study. They were maintained on ordinary laboratory chow ad libitum with humane care. Livers were removed under pentobarbital anesthesia, cut into small strips less than $1 \mathrm{~mm}$ thick, and fixed in $2.0 \%$ glutaraldehyde solution (0.1M cacodylate buffer ( $\mathrm{pH} 7.4)$ with $10 \%$ sucrose) for 30 mins at $4^{\circ} \mathrm{C}$. After a wash in a cacodylate buffer (0.1 M, pH 7.4) for 3 hrs, the samples were cut into $40-\mu \mathrm{m}$ sections with either a Vibratome or a freezing microtome. Cytochemical detection of G6PD was performed as previously described (Ishibashi et al. 1999; Matsubara et al. 2001a; 2001b; in press). In brief, sections were incubated for 60 mins at $37^{\circ} \mathrm{C}$ in the dark in a reaction medium consisting of $10.5 \mathrm{mM} \mathrm{G6P}$ (disodium salt), $70 \mathrm{mM}$ phosphate buffer ( $\mathrm{pH} 7.2), 1.3 \mathrm{mM}$ 

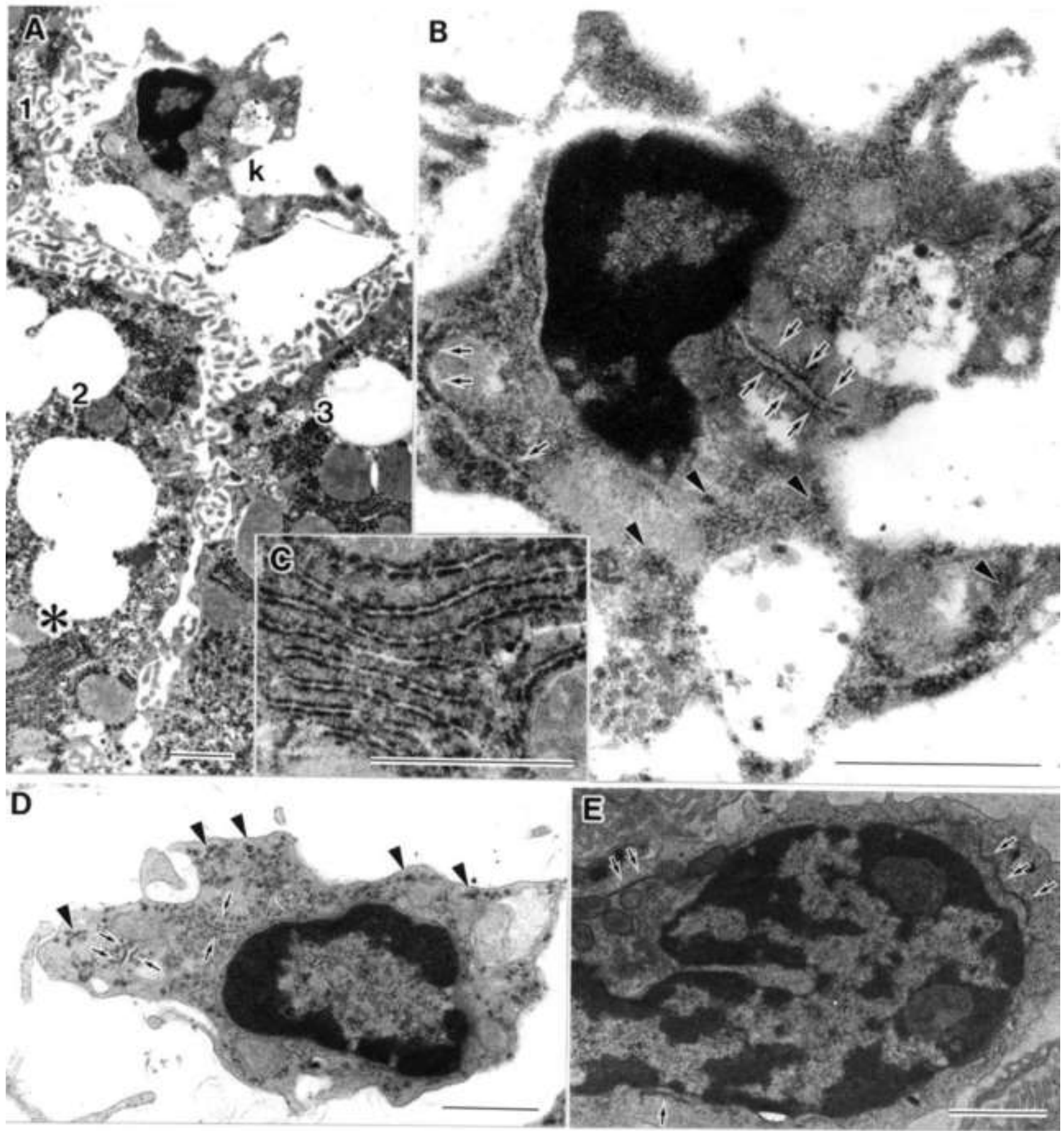

Figure 1. Enzyme-cytochemically detectable G6PD activity in rat Kupffer cells and its cytochemical control. Bar $=1 \mu \mathrm{m}$. (A) Three hepatocytes (numbered 1, 2, and 3) and one Kupffer cell (k) are visible. Electron-dense deposits for G6PD are visible in the cytoplasm of the Kupffer cells and the hepatocyte, but their subcellular localization is not confirmed at this low magnification. The Kupffer cell and the area indicated by an asterisk (cytoplasmic area in the number $\mathbf{2}$ hepatocyte) are shown at a higher magnification in (B) and (C), respectively. (B) G6PD labeling is visible in the cytoplasm (arrowheads) and on the cytosolic side of the ER membrane (arrows). (C) The cytosolic side of the ER membrane of hepatocytes also exhibit enzyme labeling. (D) Another Kupffer cell. G6PD labeling is visible in the cytoplasm (arrowheads) and in close association with the ER (arrows). (E) A Kupffer cell from cytochemical negative control, shown at the same magnification as (D). The sections were incubated in a medium lacking NADP. Although this electron micrograph showes a little low contrast, and although this cell possesses darker cytoplasm and slightly narrower ER compared to the cell indicated in (D), it is evident that both cytoplasm and ER (arrows) are devoid of G6PD labeling. Counterstained ribosomes are visible on the rough ER, but their electron-density and dot-like distribution pattern clearly distinguish them from the G6PD labeling on the ER. 
NADP, $10 \mathrm{mM}$ sodium citrate, $1.5 \mathrm{mM}$ copper sulfate, $0.5 \mathrm{mM}$ potassium ferricyanide, $1.0 \mathrm{mM}$ phenazine methosulfate, and $267 \mathrm{mM}$ sucrose. Sections were postfixed in $1.0 \%$ buffered osmium tetroxide for 60 mins at $4^{\circ} \mathrm{C}$, dehydrated, and embedded in epoxy resin. Ultrathin sections were prepared using an LKB ultrotome, and observed under a Hitachi H-7000 transmission electron microscope. G6PD activity is visible as electrondense deposits of copper ferrocyanide via the following mechanism; G6P (the substrate) oxidation by enzyme G6PD generates free electron $(\mathrm{H}+$ ), which is transferred to NADP and further to phenazine methosulfate (an exogenous electron carrier), finally trapped by ferricyanide, leading to electron-dense copper-ferrocyanide formation at the exact site of G6PD enzyme molecule (Ishibashi et al. 1999). Cytochemical control experiments were performed as follows: (1) Sections were incubated in a medium (a) lacking substrate (G6P), (b) devoid of NADP, or (c) containing $2.0 \mathrm{mM}$ p-chloromercuribenzoate (an inhibitor of G6PD activity); and (2) Sections were heated at $100{ }^{\circ} \mathrm{C}$ for $10 \mathrm{~min}$, then incubated in the complete reaction medium.

\section{Results}

Among several types of cells in and around the liver sinuses, Kupffer cells were identified by 1) their location in the liver sinusoidal lumen and not the Disse space, and 2) the presence of at least one cytoplasmic vacuole (a phagosome-like structure) and some cytoplasmic processes. Electron-dense precipitates of copper ferrocyanide indicating G6PD activity were visible in the cytoplasm and on the cytosolic side of the endoplasmic reticulum (ER) of Kupffer cells (Figures A, B, D). The intensity and distribution showed no regional/zonal differences within the liver tissue and no inter-subject differences among the rats studied. The hepatocytes also exhibited G6PD labeling throughout the cytoplasm and in close association with the ER (Figures $A, C$ ). Modifications of the reaction media such as omission of the substrate (G6P), deletion of NADP (figure $E$ ), and addition of $p$-chloromercuribenzoate, abolished the deposits indicative of G6PD activity. Deposits disappeared in the specimens heated at $100^{\circ} \mathrm{C}$ before reaction.

\section{Discussion}

Light microscopic enzyme-histochemistry (the nitroblue tetrazolium method) had suggested the presence of G6PD in rat Kupffer cells (Hosemann et al. 1979), but confirmation was not obtained due to methodological limitations. Formazan, a reaction product indicating G6PD activity, did not give sufficient electron-dense precipitate. Thus, the subcellular localization of this enzyme within Kupffer cells remained to be determined. Here, ultrastructural enzyme-cytochemistry has for the first time demonstrated the subcellular localization of Kupffer cell G6PD, consistent with findings in other cells including rat hepatocytes (Ishibashi et al. 1999), human placental villous trophoblasts (Matsubara et al. 2001a), human fetal membrane chorion laeve cytotrophoblasts (Matsubara et al. 2001b), and rat lung alveolar type II epithelial cells (Matsubara et al. 2002). Biochemical (Ozols 1993) and immunoelectron microscopic (Ninfali et al. 2000) analysis also indicated that G6PD resided both in cytoplasm and in close association with the ER in rabbit hepatocytes and rat central nervous system neurons, respectively. Furthermore, cytochemical control experiments confirmed the specific detection of G6PD activity. Quite recently, Frederiks and Vreeling-Sindelarova (2001), using the copper ferrocyanide enzyme-cytochemistry method, localized G6PD activity in rat hepatocytes. Deposits were visible not only in cytoplasm/ER but also in peroxisomes. In their experiments milder fixation procedure (semipermeable membrane technique with $0.025 \%$ glutaraldehyde) was employed, which may account for the slightly different results regarding G6PD activity in peroxisomes.

Regarding the biological significance of Kupffer cell G6PD, two possible roles can be considered. First, this G6PD may play a role in the defense of the liver against various exogenous noxious stimuli, by delivering NADPH to NADPH-dependent phagocytosis-related enzymes such as NADPH oxidase and nitric oxide synthase which Kupffer cells possess. Phagocyte activation has a close association with G6PD activity not only in various non-Kupffer phagocytic cells (Costa Rosa et al. 1992; Corraliza et al. 1993) but also in Kupffer cells (Spolarics and Navarro 1994; Spolarics and Wu 1997). In rat bone marrow-derived macrophages, G6PD activity correlated well with both macrophage stimulation status and the nitric oxide synthase activity (Corraliza et al. 1993). In rat Kupffer cells, lipopolysaccharide (Spolarics and Navarro 1994) and tumor necrosis factor- $\alpha$ (Spolarics and Wu 1997) induced an increase in the enzymatic activity and 
mRNA expression of G6PD. Second, the G6PD of activated Kupffer cells, on the other hand, may worsen liver diseases. It was reported that stimulated phagocytic cells will attack the host itself in many pathological conditions, including chronic lung disease (Snider et al. 1991) and infectionassociated preterm labor onset (Matsubara et al. 1998; 1999). Activated rat Kupffer cells, releasing reactive oxygen species around the liver tissue environment, also contributed to endotoxin-induced hepatic failure (Spolarics 1996). Considering the proposed role of Kupffer cell G6PD as an NADPHsupplier to NADPH-dependent bactericidal enzymes, it may play an important role in the pathogenesis and pathophysiology of infection/inflammation-related liver disorders. However, in the present study we found no direct evidence to support this, thus this remains hypothetical, though reasonable.

It was reported that two fractions of G6PD (cytosolic and ER-associated) possess slightly different enzymological characteristics, suggesting that they perform different functions within cells (Ozols 1993). Using G6PD enzyme-cytochemistry, one can directly compare the staining intensities/patterns of these two G6PD fractions within a single cell. Furthermore, the intensity and distribution of G6PD labeling in Kupffer cells may vary among cells at the subcellular level in both normal and pathological liver according to the activation state of the cells. The newly-developed enzymecytochemistry for G6PD may be a good tool for elucidating the role that this Kupffer enzyme plays in both the physiology and pathophysiology of the liver.

\section{Acknowledgments}

We would like to thank Dr Kentaro Sugano, Dr Ken-ichi Ido, and Dr Kiichi Tamada (Division of Gastroenterology, Department of Internal Medicine, Jichi Medical School), and Dr Shin-ichi Tominaga (Department of Biochemistry, Jichi Medical School, Tochigi, Japan) for their helpful comments for this study.

\section{References}

Corraliza IM, Campo ML, Fuentes JM, Campos-Portuguez S, Soler G. Parallel induction of nitric oxide and glucose-6-phosphate dehydrogenase in activated bone marrow derived macrophages. Biochem Biophys Res Commun 1993;196:342-7.

Costa Rosa LFBP, Cury Y, Curi R. Effects of insulin, glucocorticoids and thyroid hormones on the activities of key enzymes of glycolysis, glutaminolysis, the pentose-phosphate pathway and the Krebs cycle in rat macrophages. J Endocrinol 1992;135:213-9.

Curnutte JT. Disorders of phagocyte function. In: Hematology, basic principles and practice. Hoffman R, Benz EJ, Shattil SJ, Furie B, Cohen HJ, Silberstein LE, Eds. Churchill Livingstone: New York; 1995. p.792-818.

Frederiks WM, Vreeling-Sindelarova H. Localization of glucose-6phosphate dehydrogenase activity on ribosomes of granular endoplasmic reticulum, in peroxisomes and peripheral cytoplasm of rat liver parenchymal cells. Histochem J 2001;33:345-53.

Hosemann W, Teutch HF, Sasse D. Identification of G6PDH-active sinusoidal cells as Kupffer cells in the rat liver. Cell Tissue Res 1979; 196:237-47.

Ishibashi T, Takizawa T, Iwasaki H, Saito T, Matsubara S, Nakazawa E, et al. Glucose-6-phosphate dehydrogenase cytochemistry using a copper ferrocyanide and its application to rapidly frozen cells. Histochem Cell Biol 1999;112:221-32.

Matsubara S, Minakami H, Yamada T, Koike T, Izumi A, Takizawa T, et al. Stimulated Hofbauer cells in the placental villi from patients with second-trimester abortions. Acta Histochem Cytochem 1998;31: 447-52.

Matsubara S, Yamada T, Minakami H, Watanabe T, Takizawa T, Sato I. Polymorphonuclear leukocytes in the fetal membranes are activated in patients with preterm delivery: ultrastructural and enzyme-histochemical evidence. Placenta 1999;20:185-8.

Matsubara S, Takizawa T, Suzuki T, Minakami H, Sato I. Glucose-6phosphate dehydrogenase is present in normal and preeclamptic placental trophoblasts -ultrastructural enzyme-histochemical evidence. Placenta 2001;22:90-5.

Matsubara S, Takizawa T, Takayama T, Iwasaki R, Minakami H, Sato I. Cytochemically detectable glucose-6-phosphate dehydrogenase is present in human fetal membrane chorion laeve trophoblasts. Placenta 2001;22:613-6.

Matsubara S, Kato T, Oshikawa K, Yamada T, Takayama T, Koike T, et al. Glucose-6-phosphate dehydrogenase in rat alveolar epithelial cells: an ultrastructural enzyme-cytochemical study. Eur J Histochem 2002;46:243-8.

Ninfali P, Biagiotti E, Guidi L, Malatesta M, Gazzanelli G, Grande PD. Cytochemical and immunocytochemical methods for electron microscopic detection of glucose-6-phosphate dehydrogenase in brain areas. Brain Res Protocol 2000;5:115-20.

Ozols J. Isolation and the complete amino acid sequence of luminal endoplasmic reticulum glucose-6-phosphate dehydrogenase. Proc Natl Acad Sci USA 1993;90:5302-6.

Snider GL, Ciccolella DE, Morris SM, Stone PL, Lucey EC. Putative role of neutrophil elastase in the pathogenesis of emphysema. Ann N Y Acad Sci 1991;624:45-59

Spolarics Z, Navarro L. Endotoxin stimulates the expression of glucose-6-phosphate dehydrogenase in Kupffer and hepatic endothelial cells. J Leukocyte Biol 1994;56:453-7.

Spolarics Z. Endotoxin stimulates gene expression of ROS-eliminating pathways in rat hepatic endothelial and Kupffer cells. Am J Physiol 1996;270:G660-6.

Spolarics Z, Wu JX. Tumor necrosis factor alpha augments the expression of glucose-6-phosphate dehydrogenase in rat hepatic endothelial and Kupffer cells. Life Sci 1997;60:565-71. 